\title{
Heterogeneous ozonation kinetics of 4-phenoxyphenol in the presence of photosensitizer
}

\author{
S. Net, L. Nieto-Gligorovski, S. Gligorovski, and H. Wortham \\ Universités d'Aix-Marseille I, II, III - CNRS UMR 6264: Laboratoire Chimie Provence Equipe Instrumentation et Réactivité \\ Atmosphérique Case courrier 29, 3 place Victor Hugo, 13331 Marseille Cedex 03, France
}

Received: 29 September 2009 - Published in Atmos. Chem. Phys. Discuss.: 15 October 2009

Revised: 17 December 2009 - Accepted: 17 December 2009 - Published: 15 February 2010

\begin{abstract}
In this work we have quantitatively measured the degradation of 4-phenoxyphenol adsorbed on silica particles following oxidative processing by gas-phase ozone. This was performed under dark conditions and in the presence of 4carboxybenzophenone under simulated sunlight irradiation of the particles surface.

At the mixing ratio of $60 \mathrm{ppb}$ which corresponds to strongly polluted ozone areas, the first order of decay of 4-phenoxyphenol is $k_{1}=9.95 \times 10^{-6} \mathrm{~s}^{-1}$. At a very high ozone mixing ratio of $6 \mathrm{ppm}$ the first order rate constants for 4-phenoxyphenol degradation were the following: $k_{1}=2.86 \times 10^{-5} \mathrm{~s}^{-1}$ under dark conditions and $k_{1}=5.58 \times 10^{-5} \mathrm{~s}^{-1}$ in the presence of photosensitizer $(4-$ carboxybenzophenone) under light illumination of the particles surface. In both cases, the experimental data follow the modified Langmuir-Hinshelwood equation for surface reactions. The Langmuir-Hinshelwood and Langmuir-Rideal mechanisms for bimolecular surface reactions are also discussed along with the experimental results.

Most importantly, the quantities of the oligomers such as 2-(4-Phenoxyphenoxy)-4-phenoxyphenol and 4-[4-(4Phenoxyphenoxy)phenoxy]phenol formed during the heterogeneous ozonolysis of adsorbed 4-phenoxyphenol were much higher under solar light irradiation of the surface in comparison to the dark conditions.
\end{abstract}

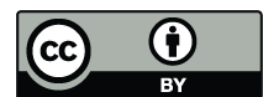

Correspondence to: S. Gligorovski (saso.gligorovski@univ-provence.fr)

\section{Introduction}

The emissions of various types of biomass combustion, such as natural fires, prescribed burns and residential wood burning, contribute significant amounts of aerosol particles to the troposphere (Anastasio et al., 1997).

Atmospheric organic aerosols emerging from biomass burning processes comprise of a large fraction of phenols and substituted phenols such as 4-phenoxyphenol (4-PP) and aromatic carbonyl compounds (e.g., 4-carboxybenzophenone 4-CB) (Simoneit et al., 1993; Jang and McDow, 1995, 1997; Anastasio et al., 1997; Vione et al., 2006). In particular, very high concentrations of aromatic carbonyl compounds and phenolic substances have been detected in aerosols and fogs in regions affected by winter residential wood burning.

In addition, phenolic substances and aromatic carbonyls can emerge as photolysis products of polycyclic aromatic hydrocarbons (PAH) which are also formed during the biomass combustion processes (Kamens et al., 1989; Vione et al., 2006). The impact of biomass burning on global tropospheric ozone concentrations was investigated due to the particular role of ozone for atmospheric chemistry and climate (e.g., Lelieveld and Dentener, 2000; Marufu et al., 2000; Galanter et al., 2000; Granier et al., 2000). All studies estimate the contribution of biomass burning to the global tropospheric ozone concentration in the order of $10 \%$. Nevertheless, on a regional scale close to the source region, biomass burning contributes, to a much larger extent, to the ozone concentration (Marufu et al., 2000).

From a health point of view, it is important to note that organic coated particles play an important role in the toxicity and safety assessment of nanoparticles which means there is an increased risk that people exposed to them are endangering their health (Warheit, 2004). 
In the last decade, a lot of interest has been drawn towards heterogeneous ozone and $\mathrm{OH}$ reactions on the atmospheric aerosol surfaces leading to the conclusion that heterogeneous chemistry plays an important role in atmospheric organic particles (Donahue et al., 2009). On the other hand, only a few studies were devoted to the light-induced heterogeneous reactions (e.g., George et al., 2005; Gomez et al., 2006, Jammoul et al., 2008).

The near-UV/vis light-absorbing organic species present on/in the condensed aerosol particles interacting with trace gases such as ozone can initiate a new and potentially important photoinduced heterogeneous chemistry.

For example, recent results from the group of George (Jammoul et al., 2008; Nieto-Gligorovski et al., 2008; Stemmler et al., 2006, 2007) and our group (Net et al., 2009; Nieto-Gligorovski et al., 2009) have shown that photosensitized and photoenhanced heterogeneous reactions can take place on the aerosol surfaces. These kind of reactions can modify the particle properties by the formation of large molecular mass compounds and can induce the development of small volatile organics which are emitted in the atmosphere.

Net et al. (2009) have shown that photo-induced heterogeneous reactions of ozone with 4-PP in the presence of 4$\mathrm{CB}$ yield large organic molecules with molecular mass up to $300 \mathrm{Da}$. However, the exact role of 4-CB as photosensitizer during the heterogeneous ozonolysis remained an open issue. In the Net et al. (2009) paper, it was suggested that the presence of 4-CB does not impact on the formation of the reaction products (surface bound and gas-phase products) but it can rather influence the kinetics. Therefore, in this study, we focused on the kinetic measurements of heterogeneous reactions between gas-phase ozone and silica particles coated with either 4-PP or with the mixture of 4-PP/4$\mathrm{CB}$. The kinetic data set was obtained by treating the reaction samples with Gas Chromatography Mass Spectrometry (GC-MS) coupled with the derivatization technique. Two kinetic datasets were obtained: (i) heterogeneous reactions of ozone with silica particles coated with 4-PP, (ii) light induced heterogeneous reactions of ozone with silica particles coated with the mixture of 4-PP/4-CB. The obtained first order rate constants were plotted as a function of the ozone concentrations. The comparison of the two datasets demonstrates an enhancement of the first order rate constants by a factor of two in the presence of light and photosensitizer (4-CB) and by this we revealed the importance of a photosensitizer such as 4-CB in the heterogeneous ozone reactions which occur on the aerosol surfaces. A previously modified and adopted Langmuir-Hinshelwood mechanism (see e.g., Pöschl et al., 2001; Ammann et al., 2003; Mmereki et al., 2004) was applied to fit the experimental observations.

The evolving of the organics emerged from the heterogeneous ozonolysis of 4-PP in presence and in absence of photosensitizer was observed, as well.

\section{Experimental}

\subsection{Experimental set-up}

Mineral dust, of which silica is commonly a major constituent (Usher et al., 2003) adsorbs organic compounds which are (photo)oxidized during their transport (Falkovich et al., 2004). To study the kinetic reactions of ozone with 4-PP and to evaluate the role of 4-CB at the particle surface, the organic compounds (4-PP and/or 4-CB) were coated on the silica particles (AEROSIL R812) via liquid-solid adsorption. Silica particles are characterised by a high surfaceto-volume ratio that makes them ideal for investigation of surface-specific reactions. The experimental set-up has been explained in our previous paper (Net et al., 2009) so here only a brief description is given.

The solution of 4-PP and/or 4-CB ( $\sim 40 \mathrm{mg}$ in $100 \mathrm{ml}$ of dichloromethane) was mixed with $2 \mathrm{~g}$ of $\mathrm{SiO}_{2}$ powder, in a pyrex bulb with a volume of $500 \mathrm{~cm}^{3}$. This bulb was wrapped with aluminium foil and then ultrasonicated about $30 \mathrm{~min}$ to obtain homogeneous particles. After that, this bulb was attached to a rotary evaporator where the particles were dried for $60 \mathrm{~min}$ at $40^{\circ} \mathrm{C}$ and $850 \pm 85 \mathrm{mbar}$. The prepared particles were then additionally dried about $15 \mathrm{~min}$ by nitrogen gas prior to proceeding with the kinetic experiments. Assuming a uniform particle surface coverage, the amount of 4-PP adsorbed on silica particles were below a monolayer. $2 \mathrm{~g}$ of used silicon oxide corresponds to a total specific surface of $520 \mathrm{~m}^{2}\left(260 \pm 30 \mathrm{~m}^{2} \mathrm{~g}^{-1}\right.$ from supplier). Assuming a spherical geometry, $40 \mathrm{mg}$ of 4-PP and of 4-CB possess a surface of $225 \mathrm{~m}^{2}$ and $268 \mathrm{~m}^{2}$, respectively. The percentage of aerosol surface coated with 4-PP was $\sim 43 \%$ and with 4$\mathrm{CB}$ was $\sim 50 \%$ of monolayer and the average 4 -PP or 4 -CB loading on the silica particle was $\sim 2 \%$ by weight.

All experiments were performed at an ambient temperature ( $297 \mathrm{~K})$. About $300 \mathrm{mg}$ ( $\sim 6 \mathrm{mg}$ of 4 -PP or 4-CB) of obtained particles were transferred into other pyrex bulbs with a volume of $500 \mathrm{~cm}^{3}$. The coated silica particles were then exposed to a broad range of ozone mixing ratios between $60 \mathrm{ppb}$ and $6 \mathrm{ppm}$. In another independent experiment, dried coated silica particles were simultaneously exposed to ozone and transversally irradiated with simulated sunlight emitted from a broadband continuous light source such as a xenon lamp $\left(700 \mathrm{~W} \mathrm{~m}^{-2}\right.$ for $315-400 \mathrm{~nm}$ and $160 \mathrm{~W} \mathrm{~m}^{-2}$ for $400-$ $700 \mathrm{~nm}$ ) at a distance of $10 \mathrm{~cm}$ from the bulb. The rotation of the bulb ensured a homogeneous irradiation of the particles during the whole experiment.

\subsection{Chemicals and reagents}

The standards for the identification of the following compounds: 4-carboxybenzophenone, 4-phenoxyphenol, phenol, hydroquinone, catechol, 4-hydroxybenzoic acid, benzoic acid, fumaric acid, terephtalic acid, maleic acid, 1,2,4trihydroxybenzene and 4,4'-dihydroxydiphenyl ether were 
provided from Sigma Aldrich, CHIMICA, TCI Europe Laboratory Chemicals with purity $\geq 98 \%$.

The $\mathrm{SiO}_{2}$ powder AEROSIL ${ }^{\circledR} \mathrm{R} 812$ with purity $\geq 99.8 \%$, average size of $7 \mathrm{~nm}$ and specific surface of $260 \pm 30 \mathrm{~m}^{2} \mathrm{~g}^{-1}$ were supplied by Evonik (France).

\subsection{Gas Chromatography-Mass Spectrometry (GC-MS) analysis}

Following the reaction times of $1,2,4,6$ and $8 \mathrm{~h}$ the adsorbed organic material of the silica particles was extracted in dichloromethane (DCM) by ultrasonication (Branson 3510 , USA) for a time period of about $30 \mathrm{~min}$. The obtained suspension of coated particles was further centrifuged $6000 \mathrm{r} / \mathrm{min}$ (Sorvall LEGEND MICRO17, Electron Corp., TermoFisher). The obtained clear solutions were then analysed by GC-MS using electron impact ionisation $(70 \mathrm{eV})$ according to the following parameters: column THERMO TR5MS (internal diameter $0.25 \mathrm{~mm}$, length $30 \mathrm{~m}$, film thickness $0.25 \mu \mathrm{m}$ ), injection volume: $1 \mu \mathrm{l}$, inlet temperature: $250^{\circ} \mathrm{C}$, interface temperature: $330^{\circ} \mathrm{C}$, with the following temperature program: hold $1 \mathrm{~min}$ at $80^{\circ} \mathrm{C}$; increase temperature to 220 at a rate of $15^{\circ} \mathrm{C} / \mathrm{min}$; increase temperature to 300 at $25^{\circ} \mathrm{C} / \mathrm{min}$; hold $15 \mathrm{~min}$ at $300^{\circ} \mathrm{C}$. A Combi PAL autosampler was used to allow automated analysis. For reagent analysis, the samples were injected in the split (1/100) injection mode. For products analysis, the samples were injected in the splitless injection mode. The injector was switched to split mode $1 \mathrm{~min}$ after an injection was made.

Mass chromatograms were taken before and after the simultaneous ozone and light exposure of the organic coated silica particles. These spectra were obtained using GC-MS coupled to a derivatization analytical technique as reported in a previous paper (Net et al., 2009).

\subsection{Calibration and method validation}

(a) Selectivity

The selectivity was assessed by comparing the chromatograms of 5 blanks of pure silica particles and 5 blank samples (silica particles coated with 4-PP and 4-CB before the exposure) with the corresponding sample after the simultaneous ozone and light exposure. Each blank sample was tested using the proposed coating preparation, experimental procedure and GCMS conditions to ensure no interference peak of organic compounds in the sample.

\section{(b) Homogenization of the adsorption test}

Ten points of coated particles extracted from different sides of the bulb were analysed. Peak area ratios of the analyte to the internal standard were used to calculate the percent relative standard deviations (RSD\%). RSD\% values of $4 \%$ and $4.5 \%$ were estimated for 4-PP and 4-CB, respectively.
Internal standard used in this study was O-toluic acid and its stability in the sample was tested. The RSD\% value of 15 injections of O-toluic acid within $1 \mathrm{~h}$ interval was $4.5 \%$.

(c) Linearity of calibration curves and limit of quantification

Peak area ratios of the analytes to the internal standard were used to draw the calibration curves. Regression analysis was used to assess the linearity of the analytical method. Six point calibration curves were obtained with correlation coefficients $R^{2}>0.99$. Daily calibration curves were constructed during sample analysis. Limit of detection (LOD) (defined as a peak giving a response equal to a blank signal plus three times the standard deviation of the noise) of reagents and reaction products were calculated with a derivatization technique (for details see Net et al., 2009). Limits of quantification (LOQ) were calculated for a full scan or SIM of the signal of the MS and are as follows: $0.01 \mathrm{mg} / \mathrm{L}$ for 4-PP, $0.005 \mathrm{mg} / \mathrm{L}$ for $4-\mathrm{CB}, 0.3 \mathrm{mg} / \mathrm{L}$ for phenol, $0.08 \mathrm{mg} / \mathrm{L}$ for benzoic acid, $0.5 \mathrm{mg} / \mathrm{L}$ for maleic acid, $0.01 \mathrm{mg} / \mathrm{L}$ for catechol, $0.007 \mathrm{mg} / \mathrm{L}$ for fumaric acid, $0.05 \mathrm{mg} / \mathrm{L}$ for hydroquinone, $0.06 \mathrm{mg} / \mathrm{L}$ for 1,2,3-trihydroxybenzoic acid, $0.08 \mathrm{mg} / \mathrm{L}$ for 4 -hydroxybenzoic acid, $0.8 \mathrm{mg} / \mathrm{L}$ for terephtalic acid and $0.08 \mathrm{mg} / \mathrm{L}$ for $4,4^{\prime}$-dihydroxydiphenyl ether. These LOQ were confirmed by experimental analysis.

\section{Results}

\subsection{Kinetics of heterogeneous reactions}

Following the heterogeneous reactions between gas-phase ozone and 4-PP adsorbed on the surface of silica particles, the disappearance of 4-PP was followed by monitoring the intensity of GC-MS signals. The latter was done (1) in absence of light and (2) in the presence of photosensitizer (4$\mathrm{CB})$ under solar light irradiation. In both cases, an irreversible loss of 4-PP was observed.

The 4-PP loss is illustrated in Fig. 1 by typical profiles of its reactive normalized concentrations versus exposure time for the ozone concentrations ranging between $60 \mathrm{ppb}$ and $6 \mathrm{ppm}$. Experimental data points were fitted using simple first order exponential function. The error bars represent the $1 \sigma$ uncertainty levels based on the average of at least three repeated experiments.

The growth of the organics formed during the heterogeneous reactions was quantitatively determined. The presence of photosensitizer (4-CB) under solar light irradiation can significantly influence the evolution of the products formation. Figure 2 shows the difference in phenols evolving during ozonolysis of 4-PP under dark conditions (Fig. 2a) and under solar light illumination of the silica surface in the presence of 4-CB (Fig. 2b). 

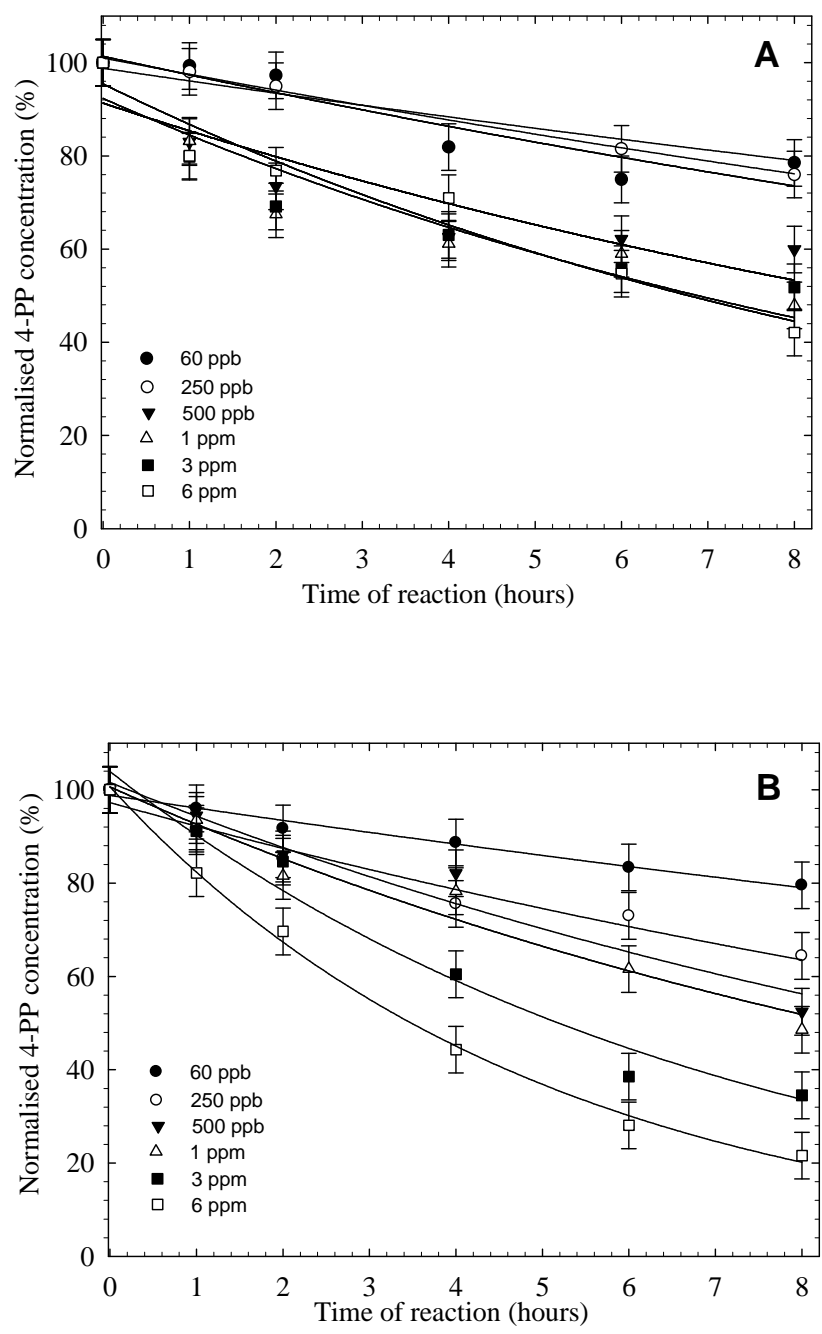

Fig. 1. Normalized concentrations of 4-PP degradation in function of time. (A) under dark conditions (B) under solar light illumination of the silica surface in presence of 4-CB. The error bars representative $1 \sigma$ uncertainty levels based on the average of at least three repeated experiments.

As can be seen, the mass of phenol expressed in mg was slightly higher in the experiment under dark condition than under solar light illumination of the surface. Typically for the first order of processes (Fig. 2a and b), there is a sharp increase in the first few hours, then a slow rise of the mass of phenol with the reaction time and with ozone concentrations. The latter clearly indicates that phenol undergoes further reaction and contributes to the formation of oligomers. This is in good agreement with the proposed reaction mechanism from our previous article (Net et al., 2009) which focused on the same reaction system. The quantities of the oligomers such as 2-(4-Phenoxyphenoxy)-4-phenoxyphenol and 4-[4-(4-Phenoxyphenoxy)phenoxy]phenol (Figs. 8s and $9 \mathrm{~s}$, respectively in the supplemental electronic material: http://www.atmos-chem-phys.net/10/1545/2010/
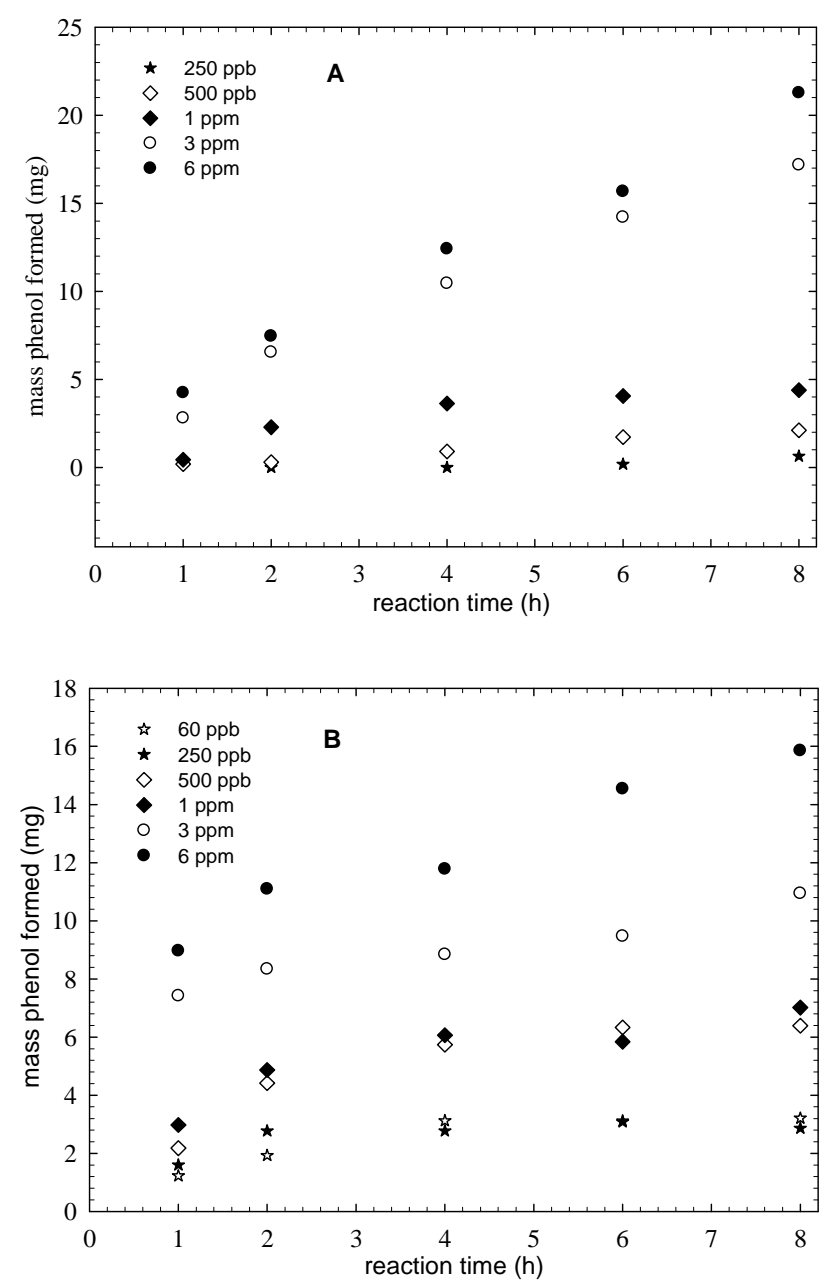

Fig. 2. Representative phenol formed during ozonolysis of 4-PP. (A) under dark condition in function of time at six ozone concentration and (B): under solar light illumination of the silica surface in presence of 4-CB in function of time at six ozone concentrations.

acp-10-1545-2010-supplement.pdf) also increase linearly in function of time and in function of ozone concentration. It is more important that both oligomers exhibited higher masses in the experiment under solar light illumination of the silica surface in presence of 4-CB in comparison to the experiment under dark conditions. The quantities of both oligomers increased rapidly in the first $4 \mathrm{~h}$ of the experiment but then their masses diminished slightly, especially at high ozone concentrations. The evolution of masses of the other products (already identified and with standards confirmed, see Net et al., 2009) formed during the ozonolysis of 4-PP under dark conditions and in the presence of 4-CB are presented in the supplemental electronic material: http://www.atmos-chem-phys.net/10/1545/ 2010/acp-10-1545-2010-supplement.pdf. 


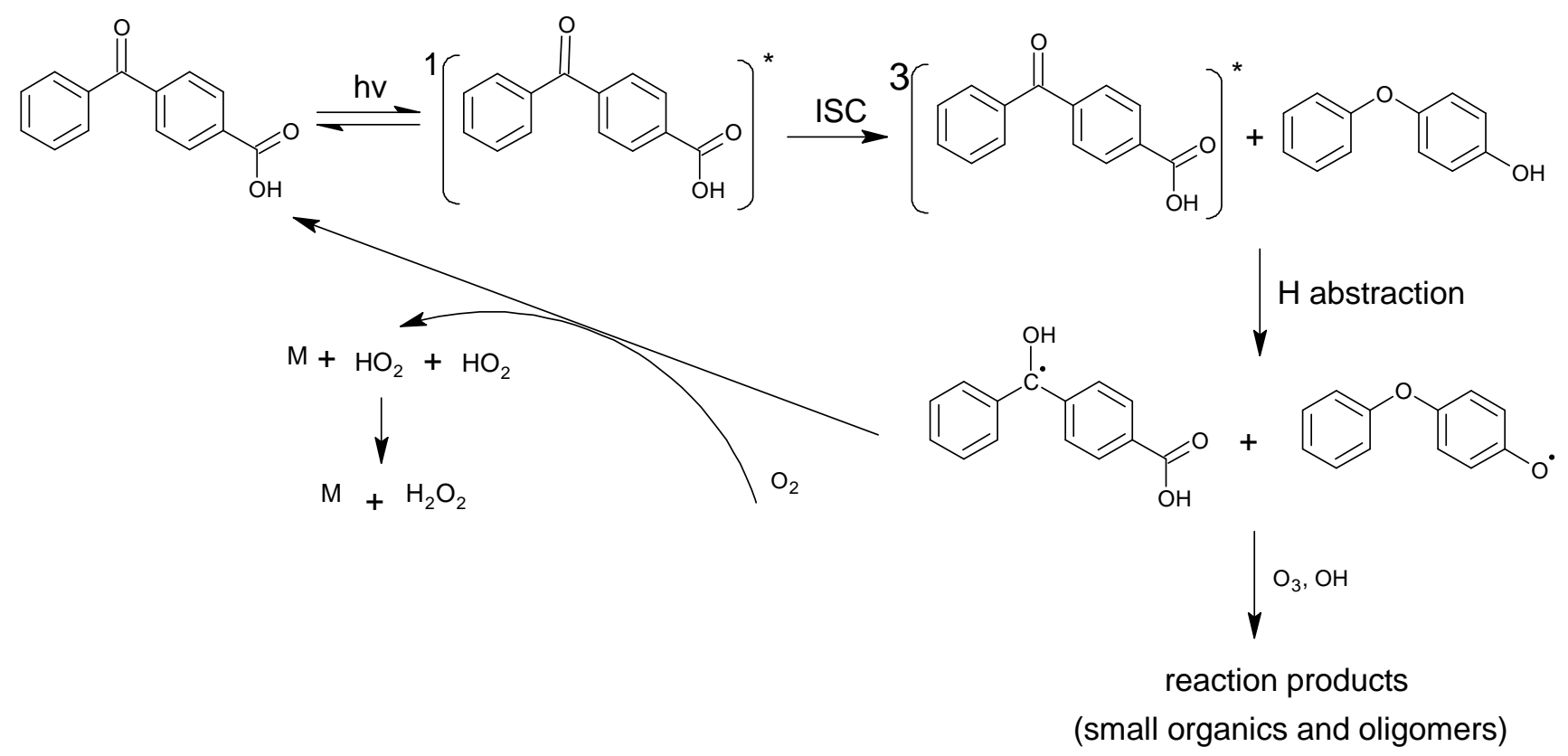

Scheme 1.

To check the possibility of $4-\mathrm{CB}$ as a mediator in the reactions between ozone and 4-PP we performed the reaction between ozone and 4-PP in absence and in presence of 4$\mathrm{CB}$ without light irradiation. No changes were observed in the degradation of 4-PP in both cases. The obtained results are presented in the supplemental electronic material (Fig. 10S: http://www.atmos-chem-phys.net/10/1545/2010/ acp-10-1545-2010-supplement.pdf).

In addition, it is noteworthy that the electron transfer mechanism between the excited triplet states of many organic compounds and molecular oxygen induces formation of electronically excited singlet state of molecular oxygen, $\mathrm{O}_{2}\left({ }^{1} \Sigma \mathrm{g}\right)$ (Styler et al., 2009). Presumably, $\mathrm{O}_{2}\left({ }^{1} \Sigma \mathrm{g}\right)$ may react with 4-PP and increase its rate of degradation under light irradiation in the absence of ozone. Such a possibility was already examined by Anastasio et al. (1997) who showed that organics such as 4-CB may act as photosensitizers and that phenols and substituted phenols such as 4-PP serve as the donor of electrons for reduction of $\mathrm{O}_{2}$ to hydrogen peroxide. Based on these findings, the mechanistic proposition is given below for the reaction between ozone and 4-PP in presence of 4-CB as a photosensitizer.

\subsection{Reaction pathway}

Independently of 4-PP degradation experiments, we checked the GC-MS intensity signals of the photosensitizer (4-CB) during the simultaneous ozonolysis and light illumination of the coated particles. At different ozone concentrations ranging from $60 \mathrm{ppb}$ to $6 \mathrm{ppm}$ and for the reaction time between

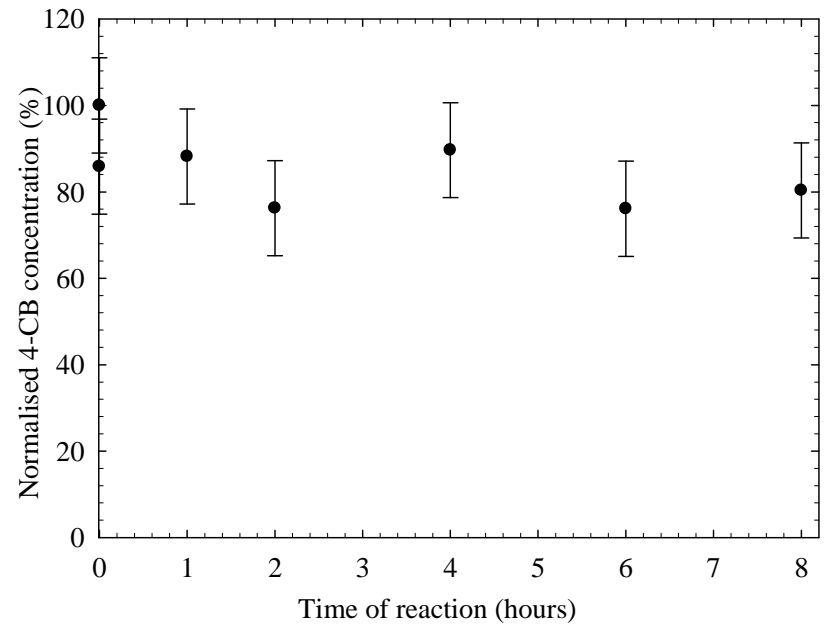

Fig. 3. Normalized concentrations of 4-CB degradation in function of time. The applied ozone mixing ratio is $6 \mathrm{ppm}$. The error bars represent the $1 \sigma$ uncertainty levels based on the average of five repeated experiments.

0 and $8 \mathrm{~h}$, the initial concentration of $4-\mathrm{CB}$ remained practically unchanged (Fig. 3).

The latter implies that the reaction pathway (note that the term reaction pathway is different from LangmuirHinshelwood mechanism and Langmuir-Rideal mechanism described in the next section) is such that it is able to restore the original sensitizer molecule (4-CB), in which case the process is photocatalytic. Typically, a photosensitized process requires absorption of light by the photosensitizer, 
followed by energy transfer or charge transfer between the excited triplet of the photosensitizer and its neighbouring molecules (in this case 4-PP). In Net et al. (2009) it was shown by ab-initio calculations that energy transfer is not possible between the excited triplet of 4-CB and 4-PP but it is rather the electron transfer or hydrogen abstraction (Canonica et al., 1995, 2000).

Recently, George et al. (2005) have reported that the excited triplet of 4-CB may initiate further photochemistry. Type II photoinitiators represent compounds which triplet excited states such as ${ }^{3} 4-\mathrm{CB}^{*}$ readily react with hydrogen donors, thereby producing an initiating radical (Davidson, 1983). Hence, in our system, ${ }^{3} 4-\mathrm{CB}^{*}$ can react with $4-\mathrm{PP}$, thus, producing an initiating radical that can further induce the formation of small volatile organics and oligomers in the presence of atmospheric oxidants $\left(\mathrm{OH}, \mathrm{O}_{3}\right)$ (Net et al., 2009). It is noteworthy that the formed radical, in presence of electron acceptors e.g., $\mathrm{O}_{2}$, can lead to the formation of hydrogen peroxide and then falls to its initial state (ground state of 4CB) (Scheme 1).

\section{Single-component heterogeneous reactions}

In photocatalysis processes, the rate of degradation increases with the concentration of the organic compound adsorbed on the surface leading to the plateaux as if the rate would be determined by the adsorption properties of the adsorbed organics. Historically, (Hoffmann et al., 1995; Minero, 1999) such behaviour of the degradation rate was interpreted in terms of two parameter saturation kinetic expression:

$r=\frac{k_{1} K_{\mathrm{X}}[\mathrm{X}]}{1+K_{\mathrm{X}}[\mathrm{X}]}$

Where $K_{\mathrm{X}}$ is the dynamic Langmuir adsorption constant of the $\mathrm{X}$ species and $[\mathrm{X}]$ is the concentration of $\mathrm{X}$ and $k_{1}$ is the observed first order rate constant.

Equation (1), known as the Langmuir-Hinshelwood model, is exclusively valid for single-component heterogeneous photocatalytic reactions and can be applied under assumptions that; (i) the reaction is surface mediated, and (ii) the reaction system is driven by the reaction kinetics and not adsorption kinetics (Peill and Hoffmann, 1998).

However, there is a huge controversy concerning the application of L-H mechanism to heterogeneous photocatalysis processes. Masel (1996) has demonstrated that although the experimental data of heterogeneous catalysis reactions were well fitted to L-H equation, this does not imply that L-H mechanism is operational. Actually, the apparent L$\mathrm{H}$ trend in photocatalysis was not attributed to the surface reactions but to the presence of so called "back reactions" that regenerate the reactant, either by reducing the oxidized intermediates or by oxidizing reduced intermediates. These processes occur to a higher extent at elevated reactant concentrations, where there is a decrease of the reaction rates and, therefore, an apparent L-H trend. For the above discussed reasons, it was concluded (Minero, 1999; Minero and Vione, 2006) that in photocatalysis processes rather a combination of processes occur that have nothing to do with L-H mechanism and they simulate L-H kinetics. This is also the reason why Langmuir adsorption constants, derived from photocatalysis, are very different from those derived from dark experiments: the former are not real adsorption constants but a combination of lumped kinetic parameters (Minero, 1999).

Equation (1) was modified and adopted for treating the bimolecular surface reactions of atmospheric relevance (see the next section). Having in mind all the mentioned uncertainties about L-H mechanism in the heterogeneous catalysis reactions, certain precautions must be taken while implementing the modified L-H mechanism into atmospheric heterogeneous chemistry.

\subsection{Modified Langmuir-Hinshelwood mechanism}

Equation (1) has been modified to deal with the bimolecular surface reactions of atmospheric relevance under assumptions that the organic compound was previously adsorbed on the surface and that the concentration of the gas-phase oxidant is in excess compared to the concentration of the adsorbed organic (see for instance Mmereki et al., 2004; Kahan et al., 2006; Kwamena et al., 2007).

Consequently, the observed rate constant $\left(k_{1 \mathrm{obs}}\right)$ of the 4PP degradation can be expressed as:

$\frac{k_{2 n d}[\mathrm{SS}] K_{\mathrm{O} 3}\left[\mathrm{O}_{3 \mathrm{~g}}\right]}{1+K_{\mathrm{O} 3}\left[\mathrm{O}_{3 \mathrm{~g}}\right]}=k_{1 \mathrm{obs}}$

where $k_{2 \text { nd }}$ is the second order rate constant, [SS] is the number of adsorption sites available for ozone, $\mathrm{K}_{\mathrm{O} 3}$ is the ozone gas-surface equilibrium constant and $\left[\mathrm{O}_{3 \mathrm{~g}}\right]$ is the gas-phase ozone concentration. The second order rate constant $k_{2 \text { nd }}$ can be obtained by plotting $k_{1 \text { obs }}$ versus $\left[\mathrm{O}_{3 \mathrm{~g}}\right]$. $k_{2 \text { nd }}$ multiplied by [SS] gives the maximum rate constant $k_{1 \text { max }}$ which is experimentally obtained at very high ozone concentrations (Kahan et al., 2006; Kwamena et al., 2007).

Equation (2) can be rewritten as:

$\frac{k_{1 \mathrm{max}} K_{\mathrm{O} 3}\left[\mathrm{O}_{3 \mathrm{~g}}\right]}{1+K_{\mathrm{O} 3}\left[\mathrm{O}_{3 \mathrm{~g}}\right]}=k_{1 \mathrm{obs}}$

It can be seen that Eq. (3) is very similar to Eq. (1) with one difference that is $k_{1}$ is replaced with $k_{1 \max }$. In Eq. (3) it is assumed that the organic compound has a very long residence time on the surface which means that it represents a part of the surface.

According to Eq. (3), $K_{O 3}$ can be obtained by fitting the experimental results, obtained from the plot of $k_{1 \mathrm{obs}}$ versus $\left[\mathrm{O}_{3 \mathrm{~g}}\right]$, to a nonlinear least-square.

In the past studies (e.g., Kwamena et al., 2006; Clifford et al., 2008; Pflieger et al., 2009a), the experimental results of heterogeneous bimolecular reactions on the surface (liquid and solid) were fitted with Eq. (3). But as mentioned above, 
this equation does not reflect the Langmuir-Hinshelwood mechanism for bimolecular surface reactions but rather unimolecular processes (see e.g., Adamson and Gast, 1997; Finlayson-Pitts and Pitts, 1983; Masel, 1996). Therefore, Eq. (3) would be better described by the use of the term modified Langmuir-Hinshelwood mechanism. As we mentioned above, L-H equation is highly controversial in heterogeneous photocatalysis processes and, therefore, certain precautions must be taken while implementing this model into atmospheric heterogeneous chemistry.

\subsection{Treatment of the kinetic data with the modified Langmuir-Hinshelwood mechanism}

In this study, the organic compounds were previously adsorbed on the silica surface and exposed to gaseous ozone which implies that modified Langmuir-Hinshelwood mechanism can be applied in this case.

By fitting the observed kinetic data for the ozonolysis of 4-PP to Eq. (3), the obtained values of $K_{O 3}$ are $(5 \pm 1) \times 10^{-14} \mathrm{~cm}^{3}$ and $(9 \pm 3) \times 10^{-14} \mathrm{~cm}^{3}$ on a $4-\mathrm{PP} / 4-\mathrm{CB}$ and on a 4-PP silica surface, respectively. These two values are very similar which implies that low concentrations of adsorbed organics do not significantly affect the ozone's surface partitioning coefficient. Moreover, these values fall in the range of the observed literature data for various solid substrates (Kwamena et al., 2004, 2006; Poeschl et al., 2001).

Figure 4 illustrates nonlinear dependence of the first-order rate constants on ozone concentrations. This result is obtained under simulated sunlight irradiation (full line) and in absence of light and photosensitizer (4-CB) (dash line) (Fig. 4).

A clear change is observed in the kinetics of the heterogeneous reaction between gas phase ozone and 4-PP at the particle surface when the surface is illuminated in the presence of $4-\mathrm{CB}$. This observation extends the number and type of systems in which a photoenhancement in heterogeneous chemical reactions has been reported (Brigante et al., 2008; Styler et al., 2009; Reeser et al., 2009; Net et al., 2010). Note that such photosensitized processes were reported in the atmospheric multiphase reactions, as well (Grgic et al., 2010).

The Langmuir-Hinshelwood and Langmuir-Rideal mechanism are depicted in the next two sections, for the bimolecular surface reactions which are valid for the more volatile organic compounds that partition between the gas-phase and the surface.

\subsection{Langmuir-Hinshelwood mechanism for bimolecular surface reactions}

It is known that, in the case of bimolecular reactions, both reactant species diffuse around until a reaction occurs. For a bimolecular process, the reaction rate is taken to be proportional to the product of the two surface concentrations.

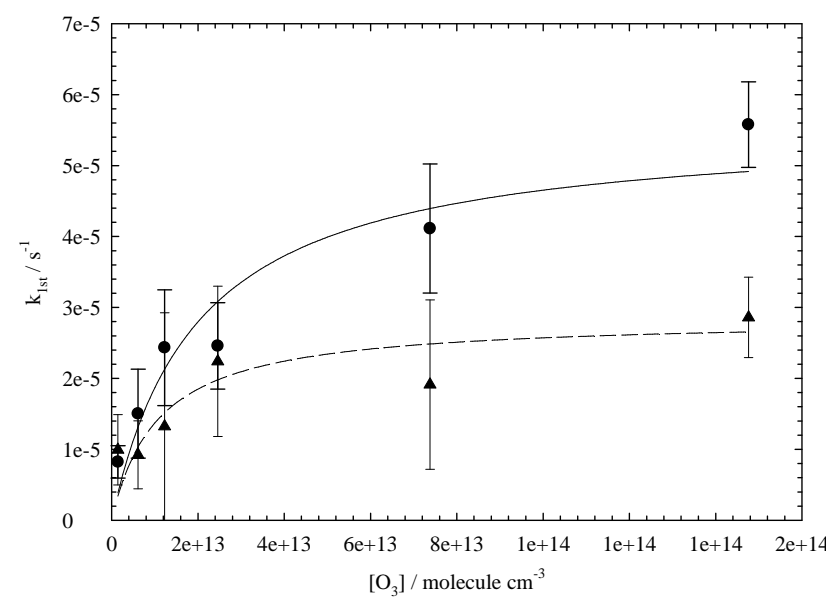

Fig. 4. First order rate constants of 4-PP degradation (derived from the slopes of the plots in Fig. 1 as a function of gas-phase ozone concentration. $\Delta$ under dark conditions, $\bullet$ under solar light irradiation of the surface in presence of 4-CB. The dashed line and solid line represent the fit of the experimental observations to the modified Langmuir-Hinshelwood mechanism (Eq. 3). Using the RSD on the scattering of the experimental data, the error on the slope $k$ was calculated using the algorithm available in the Sigma Plot software.

Hence, in the Langmuir-Hinshelwood mechanism (L-H mechanism) the two gas-phase species of interest are first adsorbed on the surface and then they react which means L$\mathrm{H}$ describes a bimolecular surface reaction between two adsorbed reactant species (see e.g., Adamson and Gast, 1997; Finlayson-Pitts and Pitts, 1983). In case of the surface reaction between adsorbed ozone and adsorbed organic compound the pseudo-first-order rate coefficient can be interpreted as follows (Finlayson-Pitts and Pitts, 1983):

$k_{1}=\frac{k_{2} K_{\mathrm{O} 3} K_{\mathrm{OC}}[\mathrm{O} 3][\mathrm{OC}]}{\left(1+K_{\mathrm{O} 3}[\mathrm{O} 3]+K_{\mathrm{OC}}[\mathrm{OC}]\right)^{2}}$

where $K_{\mathrm{O} 3}$ is the adsorption equilibrium constant of ozone, $K_{\mathrm{OC}}$ is the adsorption equilibrium constant of the organic compound, $\left[\mathrm{O}_{3}\right]$ is the gas-phase concentration of ozone and $[\mathrm{OC}]$ is the gas-phase concentration of the organic compound.

Equation (4) shows that if $[\mathrm{OC}]$ is held constant and $\left[\mathrm{O}_{3}\right]$ is varied, the reaction rate $\left(k_{1}\right)$ first increases with $\left[\mathrm{O}_{3}\right]$ and then at high ozone concentrations, $k_{1}$ decreases. A fall of $k_{1}$ arises because very high ozone concentrations yield large amounts of adsorbed ozone on the surface and correspondingly there is less quantity of organic compound.

From Eq. (4), it can be seen that for bimolecular reactions both Langmuir constants, i.e. $K_{\mathrm{oc}}$ and $K_{\mathrm{O} 3}$, are required in order to correctly describe the bimolecular surface reactions (Hoffmann et al., 1995). The Langmuir constants $K_{\text {oc }}$ and $K_{O 3}$ for sorption of each reactant are assumed to be readily determined from a classical Langmuir sorption isotherm. In this case, the surface concentrations of the reactants are 
related to their corresponding gas phase concentrations. The application of Eq. (4) will then be useful to study the heterogeneous reactions of organic compounds that partition at the gas-surface interface.

\subsection{Langmuir-Rideal mechanism for bimolecular surface reactions}

In the past studies (e.g., Miet et al., 2009; Pflieger et al., 2009a, b; Cabe and Abbatt, 2009), the bimolecular surface reactions of atmospheric relevance were discussed in term of Langmuir-Rideal mechanism known also as Eley-Rideal mechanism.

Langmuir-Rideal mechanism was presented as a simple linear regression describing a bimolecular collision between the gas phase molecule and adsorbed organics. However, such description does not reflect the Langmuir-Rideal mechanism and its accurate description is given bellow.

Langmuir-Rideal (L-R) mechanism also known as EleyRideal (E-R) mechanism describes the heterogeneous reaction between the gas-phase ozone and adsorbed organic compound on the surface and can be interpreted as follows (Finlayson-Pitts and Pitts, 1983):

$k_{1}=\frac{k_{2} K_{\mathrm{OC}}[\mathrm{O} 3][\mathrm{OC}]}{1+K_{\mathrm{O} 3}[\mathrm{O} 3]+K_{\mathrm{OC}}[\mathrm{OC}]}$

In this mechanism, only one of the molecules (organic compound) adsorbs on the surface and the other one (in this case ozone) reacts with it directly from the gas phase, without adsorbing. According to (Eq. 5) the reaction rate $\left(k_{1}\right)$ is proportional to the ozone concentrations at low $\left[\mathrm{O}_{3}\right]$ and it goes to a plateau at high $\left[\mathrm{O}_{3}\right]$.

As in the case of L-H mechanism, the Langmuir adsorption constants are required in order to determine the second order rate constant for the heterogeneous bimolecular surface reactions between gas-phase oxidants and organics that partition between the gas-surface.

\section{Conclusions and outlook}

At an atmospherically relevant ozone mixing ratio of about $60 \mathrm{ppb}$, the first order rate constant of 4-PP degradation at the silica surface is $9.95 \times 10^{-6} \mathrm{~s}^{-1}$. At extremely high ozone concentrations (see the plateau in Fig. 4) the degradation of 4-PP is enhanced by a factor of 2 in the presence of 4-CB under simulated solar irradiation compared to the dark conditions.

The evolution of the products that were already identified in Net et al. (2009) was followed under different conditions. The evolution of small organics, e.g., phenol, was more pronounced under dark conditions compared to the experiment where the surface was illuminated with the simulated solar light. On the other hand, the two oligomers i.e. 2-(4-Phenoxyphenoxy)-4-phenoxyphenol and 4-[4-(4Phenoxyphenoxy)phenoxy]phenol exhibited higher masses under solar light illumination of the silica surface in presence of $4-\mathrm{CB}$.

The first order rate constants of heterogeneous reactions between gas-phase ozone and adsorbed 4-PP on the silica surface do follow the behaviour of modified LangmuirHinshelwood mechanism (Eq. 3) which is originally valid for unimolecular surface reactions.

However, in a very recent paper by Finlayson-Pitts (2009), it was highlighted that one of the current problems in atmospheric chemistry is the Langmuir-Hinshelwood kinetics apply to different kind of solid and liquid substrates whose interactions with gas-phase ozone is not expected to be much alike. Arguably, one of the reasons for such a behaviour could be that the modified Langmuir-Hinshelwood mechanism described by Eq. (3) is not properly applied for the bimolecular surface reactions (liquid or solid surface) as we highlighted in this article. Therefore, to avoid confusion, we suggest in future studies that apply the previously adsorbed organics on the surface to avoid the use of the term Langmuir-Hinshelwood mechanism for bimolecular surface mediated reactions and to rather use the expression modified Langmuir-Hinshelwood mechanism.

In this work, we have shown that 4-CB can play an important role in enhancing the degradation of particle-adsorbed aromatic compounds such as phenols and substituted phenols in presence of ozone. It would, therefore, be very important to determine if the described process of enhanced heterogeneous reactivity upon sunlight irradiation is associated only to benzophenone and its derivatives (4-CB) as photosensitisers, or if it represents a more general phenomenon.

Keeping in mind that atmospheric aerosols contain an important fraction of photosensitizers, such as quinones and aromatic carbonyls, and knowing the potential of the photosensitizers (Anastasio et al., 1997; George et al., 2005; Vione et al., 2006) to induce phototransformation and to enhance the loss of organic molecules, further studies are recommended which include photosensitizers during the heterogeneous reactions. Although it is out of the scope of this paper, it is noteworthy that photosensitized degradation of organic compounds represents an important source of hydrogen peroxide and thus $\mathrm{OH}$ radical.

\section{References}

Anastasio, C., Faust, B. C., and Janakiram Rao, C.: Aromatic carbonyl compounds as aqueous-phase photochemical sources of hydrogen peroxide in acidic sulfate aerosols, fogs, and clouds, I. Non-phenolic methoxybenzaldehydes and methoxyacetophenones with reductants (phenols), Environ. Sci. Technol., 31, 218232, 1997.

Adamson, A. W. and Gast, A. P.: Wiley Interscience Publication, Physical Chemistry of Surfaces, John Wiley \& Sons, Inc., New York, 1997. 
Ammann, M., Pöschl, U., and Rudich, Y.: Effects of reversible adsorption and Langmuir-Hinshelwood surface reactions on gas uptake by atmospheric particles, Phys. Chem. Chem. Phys., 5, 351-356, 2003.

Brigante, M., Cazoir, D., D’Anna, B., George, C., and Donaldson, D. J.: Photoenhanced Uptake of $\mathrm{NO}_{2}$ by Pyrene Solid Films, J. Phys. Chem. A, 112, 9503-9508, 2008.

Canonica, S., Hellrung, B., and Wirz, J.: Oxidation of Phenols by Triplet Aromatic Ketones in Aqueous Solution, J. Phys. Chem. A, 104, 1226-1232, 2000.

Canonica, S., Jans, U., Stemmler, K., and Hoigne, J.: Transformation Kinetics of Phenols in Water: Photosensitization by Dissolved Natural Organic Material and Aromatic Ketones, Environ. Sci. Technol., 29, 1822-1831, 1995.

Davidson, R. S.: Advances in Physical Chemistry, edited by: Bethel, D. and Gold, V., Academic Press, London, 1983.

Falkovich, A. H., Schkolnik, G., Ganor, E., and Rudich, Y. J.: Adsorption of organic compounds pertinent to urban environments onto mineral dust particles, J. Geophys. Res., 109, D2, doi:10.1029/2003JD003919, 2004.

Finlayson-Pitts, B. J. and Pitts Jr., J. N.: Atmospheric chemistry: Fundamentals and Experimental techniques, John Wiley \& Sons, NewYork, 1986.

Finlayson-Pitts, B. J.: Reactions at surfaces in the atmosphere: integration of experiments and theory as necessary (but not necessarily sufficient) for predicting the physical chemistry of aerosols, Phys. Chem. Chem. Phys., 11, 7760-7779, 2009.

Galanter, M., Levy II, H., Carmichael, G. R.: Impacts of biomass burning on tropospheric $\mathrm{CO}, \mathrm{NOx}$, and $\mathrm{O}_{3}$, J. Geophys. Res., 105, 6633-6653, 2000.

George, C., Strekowski, R. S., Kleffmann, J., Stemmler, K., and Ammann, M.: Photoenhanced uptake of gaseous $\mathrm{NO}_{2}$ on solidorganic compounds: a photochemical source of HONO?, Faraday Discuss., 130, 195-210, 2005.

Gomez, A. L., Park, J., Walser, M. L., Lin, A., and Nizkorodov, S. A.: UV Photodissociation Spectroscopy of Oxidized Undecylenic Acid Films, J. Phys. Chem. A, 110, 3584-3592, 2006.

Granier, C., Müller, J.-F., and Brasseur, G.: The impact of biomass burning on the global budget of ozone and ozone precursors, in: Biomass Burning and its Inter-Relationship with the Climate System, edited by: Innes, J. L., Beniston, M., and Verstraete, M. M., Kluwer Academic Publishers, 2000.

Grgic, I., Nieto-Gligorovski, L. I., Net, S., Temime-Roussel, B., Gligorovski, S., and Wortham, H.: Light induced multiphase chemistry of gas-phase ozone on aqueous pyruvic and oxalic acids, Phys. Chem. Chem. Phys., 12, 698-707, 2010.

Hoffmann, M. R., Martin, S. T., Choi, W., and Bahnemannt, D. W.: Environmental Applications of Semiconductor Photocatalysis, Chem. Rev., 95, 69-96, 1995.

Jammoul, A., Gligorovski, S., George, C., and D'Anna, B.: Photosensitized Heterogeneous Chemistry of Ozone on Organic Films, J. Phys. Chem. A, 112, 1268-1276, 2008.

Jang, M. and McDow, S. R.: Benz[a]anthracene photodegradation in the presence of known organic constituents of atmospheric aerosols, Environ. Sci. Technol., 29, 2654-2660, 1995.

Jang, M. and McDow, S. R.: Product of Benz[a]anthracene photodegradation in the presence of known organic constituents of atmospheric aerosols, Environ. Sci. Technol., 31, 1046-1053, 1997.
Kahan, T. F., Kwamena, N.O.A., and Donaldson, D. J.: Heterogeneous ozonation kinetics of polycyclic aromatic hydrocarbons on organic films, Atmos. Environ., 40, 3448-3459, 2006.

Kamens, R. M., Karam, H., Guo, J., Perry, J. M., and Stockburger, L.: The Behavior of Oxy-PAH on Atmospheric Soot Particles, Environ. Sci. Technol., 23, 801-806, 1989.

Kwamena, N. O. A., Thornton, J. A., and Abbatt, J. P. D.: Kinetics of surface-bound Benzo[a]Pyrene and ozone on solid organic and salt aerosols, J. Phys. Chem. A, 108, 11626-11634, 2004.

Kwamena, N. O. A., Earp, M. E., Young, C. J., and Abbatt, J. P. D.: Kinetic and product yield study of the heterogeneous gassurface reaction of anthracene and ozone, J. Phys. Chem. A, 110, 3638-3646, 2006.

Kwamena, N. O. A., Staikova, M. G., Donaldson, D. J., George, I. J., and Abbatt, J. P. D.: Role of the aerosol substrate in the heterogeneous ozonation reactions of surface-bound PAHs, J. Phys. Chem. A, 111, 11050-11058, 2007.

Lelieveld, J. and Dentener, F. J.: What controls tropospheric ozone?, J. Geophys. Res., 105, 3531-3551, 2000.

Marufu, L., Dentener, F., Lelieveld, J., Andreae, M. O., and Helas, G.: Photochemistry of the African troposphere: Influence of biomass-burning emissions, J. Geophys. Res., 105, 1451314530, 2000

McCabe, J. and Abbatt, J. P. D.: Heterogeneous loss of gas-phase ozone on n-hexane soot surfaces: Similar kinetics to loss on other chemically unsaturated solid surfaces, J. Phys. Chem. C, 113, 2120-2127, 2009.

Miet, K., Le Menach, K., Flaud, P. M., Budzinski, H., and Villenave, E.: Heterogeneous reactions of ozone with pyrene, 1hydroxypyrene and 1-nitropyrene adsorbed on particles, Atmos. Environ., 43, 3699-3707, 2009.

Minero, C.: Kinetic analysis of photoinduced reactions at the water semiconductor interface, Catal. Today, 54, 205-216, 1999.

Minero, C. and Vione, D.: A quantitative evalution of the photocatalytic performance of $\mathrm{TiO}_{2}$ slurries, Appl. Catal. B Environ., 67, 257-269, 2006.

Net, S., Nieto-Gligorovski, L., Gligorovski, S., Temime-Roussel, B., Barbati, S., Lazarou, Y. G., and Wortham, H.: Heterogeneous light induced ozone processing on the organic coatings in the atmosphere, Atmos. Environ., 43, 1683-1692, 2009.

Net, S., Gligorovski, S., Pietri, S., and Wortham, H.: Photoenhanced degradation of veratraldehyde upon the heterogeneous ozone reactions, submitted to Phys. Chem. Chem. Phys., 2010.

Nieto-Gligorovski, L. I., Net, S., Gligorovski, S., Wortham, H., Grothe, H., and Zetzsch, C.: Spectroscopic study of organic coatings on fine particles, exposed to ozone and simulated sunlight, Atmos. Environ., doi:10.1016/j.atmosenv.2009.10.043, 2009.

Nieto-Gligorovski, L., Net, S., Gligorovski, S., Zetzsch, C., Jammoul, A., D'Anna, B., and George, C.: Interactions of ozone with organic surface films in the presence of simulated sunlight: impact on wettability of aerosols, Phys. Chem. Chem. Phys., 10, 2964-2971, 2008.

Peill, N. J. and Hoffmann, M. R.: Mathematical Model of a Photocatalytic Fiber-Optic Cable Reactor for Heterogeneous Photocatalysis, Environ. Sci. Technol., 32, 398-404, 1998.

Pflieger, M., Goriaux, M., Temime-Roussel, B., Gligorovski, S., Monod, A., and Wortham, H.: Validation of an experimental setup to study atmospheric heterogeneous ozonolysis of semi-volatile organic compounds, Atmos. Chem. Phys., 9, 
2215-2225, 2009,

http://www.atmos-chem-phys.net/9/2215/2009/.

Pflieger, M., Monod, A., and Wortham, H.: Kinetic study of heterogeneous photolysis of alachlor, trifluralin and terbuthylazine adsorbed on silica particles under atmospheric conditions, Atmos. Environ., 43, 5597-5603, 2009.

Pöschl, U., Letzel, T., Schauer, C., and Niessner, R.: Interaction of Ozone and Water Vapor with Spark Discharge Soot Aerosol Particles Coated with Benzo[ $[a]$ pyrene: $\mathrm{O}_{3}$ and $\mathrm{H}_{2} \mathrm{O}$ Adsorption, Benzo[a]pyrene Degradation, and Atmospheric Implications, J. Phys. Chem. A, 105(16), 4029-4041, 2001.

Reeser, D. I., Jammoul, A., Clifford, D., Brigante, M., D’Anna, B., George, C., and Donaldson, D. J.: Photoenhanced Reaction of Ozone with Chlorophyll at the Seawater Surface, J. Phys. Chem. C, 113, 2071-2077, 2009.

Simoneit, B. R. T., Rogge, W. F., Mazurek, M. A., Standley, L. J., Hildemann, L. M., and Cass, G. R.: Lignin pyrolysis products, lignans and resin acids as specific tracers of plant classes in emissions from biomass combustion, Environ. Sci. Technol., 27, 2533-2541, 1993.
Stemmler, K., Ammann, M., Donders, C., Kleffmann, J., and George, C.: Photosensitized reduction of nitrogen dioxide on humic acid as a source of nitrous acid, Nature, 440(7081), 195-198, 2006.

Stemmler, K., Ndour, M., Elshorbany, Y., Kleffmann, J., D’Anna, B., George, C., Bohn, B., and Ammann, M.: Light induced conversion of nitrogen dioxide into nitrous acid on submicron humic acid aerosol, Atmos. Chem. Phys., 7, 4237-4248, 2007, http://www.atmos-chem-phys.net/7/4237/2007/.

Styler, S. A., Brigante, M., D’Anna, B., George, C., and Donaldson, D. J.: Photoenhanced ozone loss on solid pyrene films, Phys. Chem. Chem. Phys., 11, 7876-7884, 2009.

Usher, C. R., Michel, A. E., and Grassian, V. H.: Reactions on Mineral Dust, Chem. Rev., 103, 4883-4939, 2003.

Vione, D., Maurino, V., Minero, C., Pelizzetti, E., Harrison, M. A. J., Olariu, R.-I., and Arsene, C.: Photochemical reactions in the tropospheric aqueous phase and on particulate Matter, Chem. Soc. Rev., 35, 441-453, 2006.

Warheit, D. B.: Nanoparticles: health impacts?, Mater. Today, 7, 32-35, 2004. 